\title{
Analgesic Efficacy and Outcome of Lumber Epidural Analgesia versus ultrasound guided Trasversus Abdominis Plane block In Laparoscopic Sleeve Gastrectomy
}

\author{
Mohamed S. Abd-El Aziz, Sherif S. Wahba, Sanaa F. Mahmoud, \\ Moustafa M. Sery, Marwa M. Salem
}

\begin{abstract}
Department of Anesthesia, Intensive care and Pain Management, Faculty of Medicine - Ain Shams University Corresponding author: Marwa M. Salem, Phone number: +201003591259, Email: marrwa.sweety@gmail.com
\end{abstract}

\begin{abstract}
Background: The transversus abdominis plane (TAP) block provide effective postoperative analgesia in lower abdominal surgery. Subcostal TAP block as a new technique to provide analgesia for the supraumbilical abdomen. Traditionally, pain relief for these patients is provided by epidural analgesia or IV opioid analgesia. Although epidural analgesia is currently the "gold standard" for postoperative pain treatment, associated complications and contraindications may limit its use. IV opioid analgesia may cause opioid-related side effects and be associated with inadequate analgesia. Aim of the Work: This study aimed at clinically evaluating and statistically comparing between lumber epidural versus transversus abdominus plane block as postoperative Analgesia for laparoscopic sleeve gastrectomy. Also, our goal was to figure out the most possible effective technique for this kind of procedure with most benefits and least side effects. Patients and Methods: This single blinded randomized clinical trial was carried out at Ain Shams University hospitals on 60 adult Bariatric patients undergoing elective Laparoscopic sleeve Gastrectomy, aged 20 to 50 years, ASA III, BMI equal or less than $45 \mathrm{Kg} / \mathrm{m}^{2}$. Results: Patients in the Lumber Epidural group had significantly less pain score when compared to the other TAP group ( $\mathrm{p}$-value $<0.001)$. And, they had longer time to first request rescue analgesia (nalbuphin) $(\mathrm{P}=0.0013)$. Also, total dose of nalbuphin consumption was less in Lumber Epidural group than TAP group $(\mathrm{P}<0.001)$. Conclusion: This study concluded that TAP block was effective in pain relief after Laparoscopic sleeve gastrectomy, however, Lumber Epidural was superior in pain relief, less narcotic consumption and overall more patient satisfaction.
\end{abstract}

Keywords: Lumber Epidural Analgesia, Trasversus Abdominis Plane block, Laparoscopic Sleeve Gastrectomy

\section{INTRODUCTION}

The recent adoption of pain assessment and management standards follows a growing recognition of the benefits of acute pain control on short-term outcomes, patient satisfaction, quality of life, and in the prevention of development of chronic pain syndromes ${ }^{(1)}$.postoperative pain seems to remain a very important factor that can deteriorate the overall quality of recovery after laparoscopic procedures (2).Opioids continue to play a major role in the pharmacologic management of acute postoperative pain but are less efficacious in treating inflammatory or neuropathic pain. Moreover, the use of opioids often leads to undesirable side effects (respiratory depression, central nervous system depression, sedation, circulatory depression, nausea, vomiting, pruritus, urinary retention, impairment of bowel function, and sleep disruption) that can hamper or delay recovery from surgery.Treatment with other non-opioid modalities (neuroaxial analgesia and peripheral nerve block techniques) has the potential advantage of providing improved analgesia and early mobilization while reducing opioid side effects ${ }^{(3)}$.Epidural anesthesia and analgesia have the potential to reduce or eliminate the perioperative physiologic stress responses to surgery and thereby decrease surgical complications and improve outcomes ${ }^{(4)}$.Transversus abdominis plane (TAP) block is a regional anesthetic technique used to block myocutaneous sensation of anterior abdominal wall. This block has a number of advantages which include technical simplicity, high analgesic effectiveness, opioid sparing, long duration of effect $(\sim 30-36$ hour), minimal side effects in comparison to that associated with neuroaxial analgesia (e.g., hypotension, motor blockade) and opioid analgesia. TAP block may be posterior or subcostal TAP block ${ }^{(5)}$.Valid and reliable pain assessment tools are essential for both clinical trials and effective pain management. Acute postoperative pain can be reliably assessed using physiologic data (heart and respiratory rates) and behavioral responses. Other diagnostic tools are used to assist in assessing the severity and quality of pain experienced by the patients such as Numeric Rating Scales(NRS) or Visual Analogue Scales (VAS). Both these are more powerful in detecting changes in pain intensity than a Verbal Categorical Rating scale (VRS) ${ }^{(6)}$.Rapid and uneventful postoperative recovery following general anesthesia in morbidly obese patients undergoing bariatric surgery may offer challenges to anesthesiologists. With improved surgical techniques and shorter pneumoperitoneum, regional anesthesia may be considered for this laparoscopic procedure in selected cases ${ }^{(7)}$. 


\section{AIM OF THE WORK}

In the present study, clinical evaluation, statistical analysis and comparison were carried out between lumber epidural versus transversus abdominus plane block as postoperative Analgesia for laparoscopic sleeve gastrectomy. Also, it aimed at figuring out the most possible effective technique for this kind of procedure with most benefits and least side effects.

\section{PATIENTS AND METHODS}

This single blinded randomized clinical trial study was carried out at Ain Shams University hospitals, after approval of institutional ethics committee and obtaining informed consent from patients. The study was performed on 60 adult Bariatric patients undergoing elective Laparoscopic sleeve Gastrectomy aged from 20 to 50 years, ASA I-II, BMI equal or less than $45 \mathrm{Kg} / \mathrm{m} 2$. Patients with Previous history of spinal surgery, kyphoscoliosis, other uncontrolled medical comorbidities (Diabetes Mellitus, Hypertension, Ischemic Heart Diseases, pulmonary hypertension, obstructive sleep apnea, Hepatic or renal impairment), coagulopathies or other bleeding disorders or on antiplatelets or anticoagulant therapy, preexisting neurologic disease, abnormal echocardiography or pulmonary function test were excluded from the study.

\section{Patients policy and procedures:}

During the preoperative assessment, all enrolled patients were informed about the study objectives and protocol. For all enrolled patients, full history, clinical examination and routine laboratory investigations were performed., they were randomly assigned into 2 groups by choosing a card, lumbar epidural analgesia (LEA group $=30$ patients), bilateral TAP block (TAP group $=30$ patients), No premedication was given.

\section{Group Lumber Epidural Analgesia} (LEA).: It was inserted before the induction of anesthesia by a 20-G epidural catheter (Perifix, B. Braun, Melsungen AG, Germany), under aseptic precautions in sitting position at the well felt inerspinous space at lumbar region, midline approach with low resistance technique with saline using an 18-G, $8 \mathrm{~cm}$ Tuohy needle (Perifix, B Braun, Melsungen AG, Germany) was used, upon reaching the Epidural space the needle is then directed upwards to guide the catheter towards the thoracic levels and the catheter will be inserted to thread $6 \mathrm{~cm}$ length inside the epidural space and then secured. Before patient's emergence from anesthesia and after end of surgery, $20 \mathrm{ml}$ of $0.25 \%$ bupivacaine was titrated $5 \mathrm{ml}$ every 2-3 minutes. Then an epidural infusion was started at the PACU by infusion pump with bupivacaine $0.125 \%$ at a rate of $5 \mathrm{ml} / \mathrm{h}$ all through the observation period of the study as a continuous epidural analgesia.

Induction was achieved as follows: (in the both groups):All patients have received general anesthesia with intravenous Fentanyl 1-2 $\mu \mathrm{g} / \mathrm{kg}$, Propofol $2 \mathrm{mg} / \mathrm{kg}$ and Tracheal intubation was done following administration of a nondepolarizing neuromuscular blocking drug (Atracurium $0.5 \mathrm{mg} / \mathrm{kg}$ ). Anesthesia was maintained with Sevoflurane $1-2 \%$ in $60 \%$ O2 in air mixture, non-depolarizing neuromuscular (Atracurium $0.1 \mathrm{mg} / \mathrm{kg}$ ) throughout the operative period. ventilation was adjusted to achieve an EtCO2 of $(35-40 \mathrm{~mm} \mathrm{Hg})$. Changes in hemodynamics were continuously monitored by ECG, non-invasive blood pressure, pulse oximetry, and capnography. Fluid plan was adjusted with lactated Ringer's solution according to fluid chart.

Group Transversus abdominus Plane Block (TAP).: In The TAP group, bilateral TAP block was performed after the end of surgery and before patient's emergence from anesthesia, with the patient in supine position and using the SONOTAP needle (21G x 150mm) under ultrasound (US) guidance. A linear high frequency (6-13 MHz) US probe (Sonosite, Bothell, WA) was used, after sheathing under aseptic precautions the probe was placed midway between the iliac crest and costal margin, and was moved medially in the oblique direction towards the costal margin until the tranversus-abdominis muscle is identified posterior to the rectus-abdominis muscle. The needle was inserted medially in line with the US probe into the fascial plane of transversusabdominis muscle, on either sides of the abdomen. Upon retrieval of the plane, $5 \mathrm{ml}$ saline $0.9 \%$ was injected to distend the transverses-abdominis plane. $20 \mathrm{ml}$ of $0.25 \%$ bupivacaine was injected slowly on each side as a single dose.

After recovery from anesthesia, patients were shifted to the post anesthesia care unit (PACU) for 2 hours. All patients were asked to give a score for their pain and pain severity was measured on arrival to the PACU (0h), 2, 4, 6, 8, 
10 and 12 hrs postoperative, using the numerical Rating scale (NRS) at rest. A score of $\leq 3$ was considered a satisfactory pain relief, while a score of $>3$ needed interference \& this interference was done at any time of pain not only the measurement times by titration of nalbuphin $(0.1 \mathrm{mg} / \mathrm{kg})$. Blood pressure (BP) and heart rate (HR) were recorded at the baseline then every $5 \mathrm{~min}$ in the first $2 \mathrm{~h}$, and then every 2 hours in the postoperative period for 12 hours. When mean blood pressure dropped below $60 \mathrm{mmHg}$, the epidural analgesia was held, the patient received 100-200 $\mathrm{ml}$ isotonic saline (0.9 $\%$ ), and IV bolus of ephedrine (3 $\mathrm{mg}$ per dose) was given. heart rate drop below50bpm was considered bradycardia and heart rate above $100 \mathrm{bpm}$ was considered tachycardia. time elapsed for recovery of bowel habit, time for ambulation was also recorded. Postoperative nausea and vomiting were also assessed using Nausea \& Vomiting Scale, Antiemetic Granisetron $(0.01 \mathrm{mg}$. $\mathrm{kg}-1)$ was given I.V. to treat any patient complained of nausea or vomiting. Patient satisfaction with analgesia were also measured by a 5-point scale offering the response options of excellent, very good, good, fair, and poor (an E5 scale) \& we gave them numbers from 0 to 4 (0: poor, 1: fair, 2: good, 3: very good, 4: excellent). Excellent, very good and good refer to patient satisfaction, on the other hand fair and poor refer to dissatisfaction.

\section{End points of the trial:}

Postoperative complications which were interfered with the use of epidural (severe hypotension) or interfered with postoperative pain assessment (post operative mechanical ventilation or disturbed conscious level). Appearance of allergy to any of the drugs used.

\section{Measurements}

The following measurements were measured and recorded: Hemodynamic data including HR, BP, were recorded every $5 \mathrm{~min}$ for the first 2 hours then every 2 hours up to 12 hours in the postoperative period in the surgical ward. Demographic data such as Age in years, height in $\mathrm{cm}$, weight in $\mathrm{Kg}, \mathrm{BMI}$ and gender.Postoperative nausea and vomiting. Time elapsed for recovery of bowel habit (starting from the end of operation).Time for ambulation (starting from the end of operation).The quality of postoperative analgesia was assessed by the anesthesiologist according to pain severity on arrival to PACU $(0 \mathrm{~h})$,
$2,4,6,8,10$, and 12 hours postoperative, using the numerical rating scale. Time to first request Nalbuphin $(0.1 \mathrm{mg} / \mathrm{kg}$ ) (Rescue Analgesia) and total dose of Nalbuphin used in each group throughout observation period (12hrs) will be recorded. Patient satisfaction and dissatisfaction with analgesia were also measured by a 5-point scale.

\section{Statistical analysis:}

Data were analyzed using Statistical package for Social Science (SPSS) version 20.0., Quantitative data were expressed as mean \pm standard deviation (SD). Qualitative data were expressed as frequency and percentage.

The following tests were used: Independent-samples $t$-test of significance was used when comparing between two means. Chisquare (X2) test of significance was used in order to compare proportions between two qualitative parameters. Mann-Whitney U Test when comparing continuous non-parametric data between independent samples. The confidence interval was set to $95 \%$ and the margin of error accepted was set to $5 \%$. So, the p-value was considered significant as the following: Probability (P-value) $\mathrm{P}$-value $<0.05$ was considered significant. $\mathrm{P}$-value $<0.001$ was considered as highly significant. P-value $>0.05$ was considered nonsignificant.

\section{RESULTS}

Our study was conducted in the period from April 2016 till June 2018. We included 60 patients who met inclusion criteria. Data from 57 patients, 29 from group TAB, 28 from group lumber epidural were included in the final analysis. 3 patients were excluded from the study due to failure of the technique. 1 from group TAB and 2 from group Lumber epidural.

Groups were comparable in demographic data (in terms of sex, age, height, weight, BMI and surgical durations) and there was no statistically significant difference between groups ( $\mathrm{p}$-value > 0.05) (table 1), Vital data in the form of noninvasive arterial blood pressure (NIABP) \& heart rate were compared in the 2 groups with no statistical difference at the baseline readings between them, and with subsequent readings there was difference between the groups. Group lumbar 
epidural showed more hypotension with significant difference between this group and the other group during the 1st $30 \mathrm{~min}$ (p-value 0.007) (table 2), As regard heart rate, there was no significant statistical difference between the two groups(table 3).As regards pain control post operatively, Numerical rating scale (NRS) was used to assess pain at rest post operatively and used at regular interval (on arrival (0h), 2h, 4h, 6h, 8h, 10h and 12hr). Lumber epidural showed the best response as regard pain control post operatively and there was statistically significant difference as regard NRS with (p-value $<0.001$ )(table 4)(figure 1). The time for the first request for Nalbuphin was significantly longer in the lumber epidural group $(310.2 \pm 23.5 \mathrm{~min})$ than in the TAP group $(290.3 \pm 20.7 \mathrm{~min}),(\mathrm{P}=0.0013)$. As regard to total dose of Nalbuphin used in each group, Lumber Epidural group used less amount of Nalbuphin than TAP group $(P<0.001)$. Furthermore, time of ambulation of each group was also recorded there was statistically significant difference between the two groups, as it was late in lumber epidural group ( $\mathrm{p}$-value <0.001). In addition, time of return of bowel movement of each group was also studied and there were no statistically difference between the two groups (pvalue 0.038) (table 5). Nausea and vomiting scores were also examined between the groups but there was no statistically significant difference (table 6).As regards to patients satisfaction and dissatisfaction with analgesia between the two groups using 5 point scale from poor to excellent, patient satisfaction for postoperative analgesia was higher in lumber epidural group than TAP group. $(\mathrm{P}=0.024)$. Regarding patient dissatisfaction the difference between the two groups was statistically insignificant ( $\mathrm{p}=0.18$ ) (table 7).

Table (1): Comparison between groups as regard demographic data.

\begin{tabular}{|l|c|c|c|}
\hline Demographic data & $\begin{array}{c}\text { TAB } \\
\text { group } \\
(\mathbf{n = 2 9 )}\end{array}$ & $\begin{array}{c}\text { Lumber epidural group } \\
(\mathbf{n = 2 8})\end{array}$ & $\begin{array}{c}\text { p- } \\
\text { value }^{\ddagger}\end{array}$ \\
\hline Sex [Female/Male] & $12 / 17$ & $13 / 15$ & 0.9 \\
\hline Age $($ years $)$ & $42 \pm 7$ & $41 \pm 7$ & 0.591 \\
\hline Height $(\mathrm{cm})$ & $163 \pm 6$ & $164 \pm 6$ & 0.531 \\
\hline Weight $(\mathrm{kg})$ & $103 \pm 8$ & $102 \pm 8$ & 0.639 \\
\hline BMI $\left(\mathrm{kg} / \mathrm{m}^{2}\right)$ & $39.6 \pm 3.1$ & $39.5 \pm 3.5$ & 0.909 \\
\hline${ }^{\ddagger}$ Data expressed as mean and standard deviation \\
\hline
\end{tabular}

Table (2): Comparison between the groups as regard mean arterial blood pressure

\begin{tabular}{|c|c|c|c|}
\hline & $\begin{array}{c}\text { TAB group } \\
(\mathbf{n = 2 9 )}\end{array}$ & $\begin{array}{c}\text { Lumber } \\
\text { epidural group } \\
(\mathbf{n = 2 8})\end{array}$ & p- value \\
\hline Base line & $67.2 \pm 11.2$ & $65.2 \pm 10.3$ & 0.48 \\
\hline $1^{\text {st } 30 ~ m i n ~}$ & $60.7 \pm 10.3$ & $52.4 \pm 12.2$ & $\mathbf{0 . 0 0 7}$ \\
\hline $1 \mathrm{~h}$ & $62.8 \pm 10.6$ & $57.5 \pm 10.3$ & 0.06 \\
\hline $2 \mathrm{~h}$ & $66.7 \pm 10.8$ & $61.6 \pm 10.3$ & 0.07 \\
\hline $4 \mathrm{~h}$ & $65.3 \pm 12.2$ & $62.2 \pm 11.2$ & 0.32 \\
\hline $6 \mathrm{~h}$ & $64.2 \pm 11.2$ & $63.3 \pm 10.2$ & 0.75 \\
\hline $8 \mathrm{~h}$ & $66.1 \pm 10.2$ & $64.3 \pm 10.4$ & 0.51 \\
\hline $10 \mathrm{~h}$ & $66.2 \pm 10.5$ & $65.1 \pm 11.2$ & 0.70 \\
\hline 12h & $66.3 \pm 10.3$ & $64.8 \pm 10.8$ & 0.59 \\
\hline "Data expressed as mean and standard deviation \\
\hline
\end{tabular}

Table (3): Comparison between the groups as regard heart rate

\begin{tabular}{|c|c|c|c|}
\hline & $\begin{array}{c}\text { TAB group } \\
(\mathbf{n = 2 9 )}\end{array}$ & $\begin{array}{c}\text { Lumber } \\
\text { epidural group } \\
(\mathbf{n = 2 8})\end{array}$ & p- value \\
\hline Base line & $85.2 \pm 11.2$ & $88.2 \pm 10.3$ & 0.29 \\
\hline $1^{\text {s }} 30 \mathrm{~min}$ & $85.7 \pm 10.3$ & $90.4 \pm 12.2$ & 0.12 \\
\hline $1 \mathrm{~h}$ & $86.8 \pm 10.6$ & $88.5 \pm 10.3$ & 0.54 \\
\hline $2 \mathrm{~h}$ & $89.7 \pm 10.8$ & $88.6 \pm 10.3$ & 0.69 \\
\hline $4 \mathrm{~h}$ & $87.3 \pm 12.2$ & $85.2 \pm 11.2$ & 0.5 \\
\hline $6 \mathrm{~h}$ & $87.2 \pm 11.2$ & $89.3 \pm 10.2$ & 0.46 \\
\hline $8 \mathrm{~h}$ & $89.1 \pm 10.2$ & $88.3 \pm 10.4$ & 0.77 \\
\hline 10h & $88.2 \pm 10.5$ & $87.1 \pm 11.2$ & 0.70 \\
\hline 12h & $86.3 \pm 10.3$ & $88.8 \pm 10.8$ & 0.59 \\
\hline 'Data expressed as mean and standard deviation \\
\hline
\end{tabular}

Table (4): Comparison between the groups as regard Numerical rating scale.

\begin{tabular}{|c|c|c|c|c|c|c|c|}
\hline & \multicolumn{3}{|c|}{ TAP } & \multicolumn{3}{|c|}{ Lumber epidural } & \multirow{2}{*}{ P value } \\
\hline & Range & Median & IQR* & Range & median & IQR* & \\
\hline On arrival & $4-6$ & 5 & $4-5$ & $2-4$ & 3 & $3-4$ & $<0.001$ \\
\hline $2 \mathrm{~h}$ & $3-5$ & 4 & $4-5$ & $1-4$ & 2 & $2-3$ & $<0.001$ \\
\hline $4 \mathrm{~h}$ & $3-6$ & 4 & $4-5$ & $1-4$ & 2 & $2-3$ & $<0.001$ \\
\hline $6 \mathrm{~h}$ & $3-6$ & 4 & $4-5$ & $0-4$ & 2 & $1-3$ & $<0.001$ \\
\hline $8 \mathrm{~h}$ & $2-5$ & 3 & $3-4$ & $1-4$ & 2 & $1-3$ & $<0.001$ \\
\hline $10 \mathrm{~h}$ & $2-5$ & 3 & $3-4$ & $0-3$ & 2 & $1-2$ & $<0.001$ \\
\hline $12 \mathrm{~h}$ & $3-6$ & 4 & $3-5$ & $0-3$ & 2 & $1-2$ & $<0.001$ \\
\hline
\end{tabular}

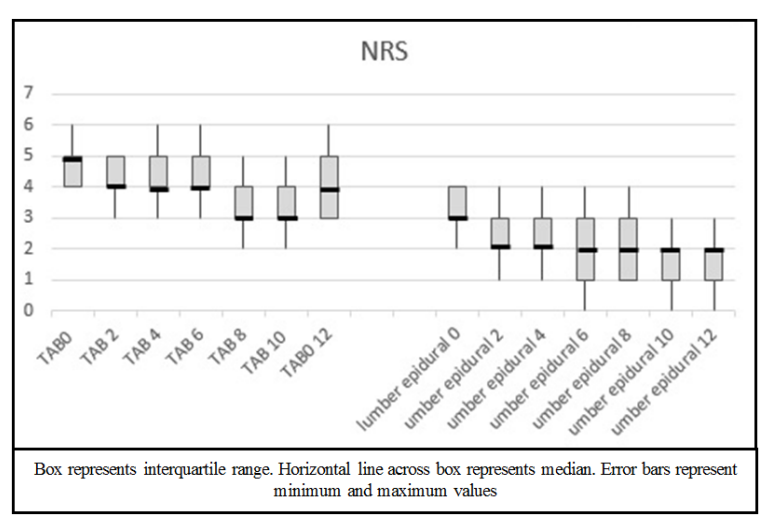

Figure(1): Box plot showing pain scores at rest in both study groups. 
Table (5): Comparison between the groups as regard to time to first request nalbuphine, total dose of nalbuphin consumption, time of ambulation, time of return of bowel movement.

\begin{tabular}{|l|c|c|c|c|}
\hline & $\begin{array}{c}\text { Lumber } \\
\text { epidural } \\
\text { group } \\
(\mathbf{n = 2 8})\end{array}$ & $\begin{array}{c}\text { TAB group } \\
(\mathbf{n = 2 9 )}\end{array}$ & t-test & $\begin{array}{c}\text { p- } \\
\text { value* }\end{array}$ \\
\hline $\begin{array}{l}\text { Time to first request nalbuphin } \\
\text { (min) }\end{array}$ & $310.2 \pm 23.5$ & $290.3 \pm 20.7$ & 3.396 & 0.0013 \\
\hline $\begin{array}{l}\text { Total dose of } \\
\text { nalbuphinconsumption (mg) }\end{array}$ & $11.2 \pm 3.1$ & $18.9 \pm 3.6$ & 7.740 & $<0.001$ \\
\hline Time of ambulation (min) & $106.6 \pm 24.2$ & $82.9 \pm 20.2$ & 3.617 & $<0.001$ \\
\hline $\begin{array}{l}\text { Time of return of bowel } \\
\text { movement (h) }\end{array}$ & $15.8 \pm 3.9$ & $18.2 \pm 4.6$ & 1.900 & 0.038 \\
\hline *Data expressed as mean and standard deviation \\
\hline
\end{tabular}

Table (6): Comparison between groups as regard to Nausia and vomiting.

\begin{tabular}{|l|c|c|c|c|c|}
\hline \multirow{2}{*}{ Nausea and vomiting } & \multicolumn{2}{|c|}{$\begin{array}{c}\text { TAB group } \\
\text { (n=29) }\end{array}$} & \multicolumn{2}{|c|}{$\begin{array}{c}\text { Lumber } \\
\text { epidural group } \\
\text { (n=28) }\end{array}$} & \multirow{2}{*}{ p-value } \\
\cline { 2 - 5 } & No. & \% & No. & \% & \\
\hline No (0) & 15 & 51.7 & 15 & 53.6 & \\
\hline Mild (1) & 6 & 20.7 & 7 & 25.0 & \multirow{2}{*}{$>0.05$} \\
\hline Moderate (2) & 4 & 13.8 & 3 & 10.7 & \\
\hline Frequent (3) & 4 & 13.8 & 3 & 10.7 & \\
\hline Severe (4) & 0 & 0 & 0 & 0 & \\
\hline
\end{tabular}

Table (7): Comparison between the groups as regard Satisfaction.

\begin{tabular}{|c|c|c|c|c|c|c|}
\hline \multirow[t]{2}{*}{ Satisfaction } & \multicolumn{2}{|c|}{$\begin{array}{c}\text { TAB group } \\
29\end{array}$} & \multicolumn{2}{|c|}{$\begin{array}{c}\text { Lumber } \\
\text { epidural } \\
\text { group } \\
28\end{array}$} & \multirow[t]{2}{*}{$\begin{array}{c}\text { p- } \\
\text { value }\end{array}$} & \multirow[t]{2}{*}{$\begin{array}{c}\text { p- } \\
\text { value }\end{array}$} \\
\hline & No. & $\%$ & No. & $\%$ & & \\
\hline Poor (0) & 6 & 20.7 & 2 & 7.1 & 0.27 & \multirow{2}{*}{0.18} \\
\hline Fair (1) & 6 & 20.7 & 4 & 14.3 & 0.77 & \\
\hline Good (2) & 9 & 31 & 5 & 17.9 & 0.4 & \\
\hline Very good (3) & 5 & 17.2 & 7 & 25 & 0.69 & \multirow{2}{*}{0.024} \\
\hline Excellent (4) & 3 & 10.4 & 10 & 35.7 & 0.049 & \\
\hline
\end{tabular}

\section{DISCUSSION}

$\begin{array}{ccc}\text { Major } & \begin{array}{c}\text { abdominal } \\ \text { changes }\end{array} & \begin{array}{l}\text { surgeries } \\ \text { responsible for }\end{array}\end{array}$ postoperative pain, various organ dysfunctions and prolonged hospitalization. Inadequate pain control is harmful and costly thus an appropriate pain therapy must be used to those patients. Regional anesthesia is an effective approach of choice for intraoperative and postoperative analgesia during abdominal surgeries. Epidural analgesia has been considered as the gold standard as it provides excellent analgesia. However, there are well known side effects and risks ${ }^{(8)}$. The transversus abdominis plane (TAP) block has been increasingly used in clinical practice as a new analgesic technique and opioid-sparing effects for both upper and lower abdominal surgeries and considered as safe alternative to neuraxial blockade in abdominal surgeries ${ }^{(9)}$.

Our study was a randomized clinical trial comparing the difference of analgesic effect of TAP block and Lumber epidural analgesia in laparoscopic sleeve gastrectomy. Sixty patients of both genders were divided into two groups (thirty in each group).Throughout the observation period (12 hrs) we used NRS to compare between the two groups as regard pain score. Patients in the Lumber epidural group had significantly less pain score at all comparison points (PACU, 2, 4, 6, 8,10, 12 hours) $(\mathrm{P}<0.001)$, time to first request for rescue analgesia $(\mathrm{P}=0.0013)$, lower doses of postoperative opioid consumption $(\mathrm{P}<0.001) \&$ they were more satisfied by their pain relief $(\mathrm{p}=0.024)$. However, they showed delayed time for ambulation $(p<0.001)$ and higher incidence of hypotension when compared with the other TAP group. On the other hand there was no significant difference between both groups as regards postoperative nausea and vomiting $(p>0.05)$, time of recovery of bowel habit $(\mathrm{p}=0.038)$.

The results of our study agrees with those of Yiquan et al. ${ }^{(10)}$ who have performed their study upon Ninety patients undergoing elective radical gastrectomy were randomized to receive either combined general-subcostal TAP anesthesia (group TAP), combined general-epidural anesthesia (group EA), or general anesthesia (group GA). Group EA was superior to group TAP regarding VAS pain scores at all comparison points (PACU,1,3,6,24,48,72 hours) ( $\mathrm{p}<0.001$ at all points) and less morphine consumption over the 24 hours ( $\mathrm{p}=0.003)$. Also there was no significant difference between group thoracic epidural and TAP block groups in time to first pass flatus $(\mathrm{p}=0.11)$, nausea and vomiting $(\mathrm{P}=0.8)$, EA group showed more hypotension $\{21 \%$ vs $0 \%$ ( $0.024)\}$ and no heart rate variability showed between two groups ( $0 \%$ in both as regard tachycardia).

These results agree with those found by Wahba and Kamal ${ }^{(11)}$, who conducted a study over 44 patients with ischemic heart disease undergoing upper abdominal surgery under general anesthesia, were assigned randomly to receive either continuous low thoracic epidural analgesia (TEA) or intermittent administration of local anesthetic of TAP block. They found that pain control was much better in TEA group than TAP group $(p<0.001)$ by 
lower visual rating score (VRS) at $(1,6,12,18,24$, 36 and 48hours). Also the time for the first request for morphine was significantly longer in the TEA group than in the TAP group $(\mathrm{p}<0.001)$ and less morphine consumption $(\mathrm{p}<0.001)$. Incidence of hypotension was significantly higher in the TEA group than in the TAP group $(\mathrm{p}=0.007)$. In addition, time to ambulation was longer in the TEA group than in the TAP group $(\mathrm{p}<0.001)$. Patient satisfaction for postoperative analgesia was significantly higher in the TEA group than in the TAP group $(\mathrm{p}=0.001)$.

However, time elapsed to pass flatus was significantly shorter in the TEA group than in the TAP group $(p=0.005)$ which is different to our results.

There is some arguments concerning TAP block. McDonnell et al. ${ }^{(5)}$, conducted a study on Thirty-two adults undergoing large bowel resection via a midline abdominal incision.They were randomized to receive standard care (morphine analgesia and regular nonsteroidal antiinflammatory drugs and acetaminophen) or to undergo TAP block in addition to standard care. They found that The TAP block reduced visual analog scale pain scores at all postoperative time points, including at $24 \mathrm{~h}(\mathrm{P}<0.05)$. Morphine requirements in the first 24 postoperative hours were also reduced $(\mathrm{P}<0.05)$. All TAP patients reported high levels of satisfaction with their postoperative analgesic regimen.

Moreover, Sherif et al. ${ }^{(12)}$ had reported Lower morphine consumption in TAP block patients than control group postoperatively in morbidly obese patients undergoing laparoscopic sleeve gastrectomy. Moreover, they found that there was a statistically significant difference between the two groups studied $(\mathrm{P}<0.001)$.

A contradictory results to our data have been reported by retrospective propensity matched cohort study done by Ayad et al. ${ }^{\text {(13). }}$ They tested the primary hypothesis that TAP infiltration are noninferior (not worse) to continuous epidural analgesia and superior (better) to intravenous opioid analgesia in patients recovering from major lower abdominal surgery. 318 patients were propensity matched among three groups (106 per group).In addition, they found that the TAP infiltration group was noninferior (not worse) to Epidural on both NRS over $72 \mathrm{~h}$ and opioid consumption (both $\mathrm{P}<0.001$ ). The tests of Epidural versus TAP infiltration did not show noninferiority on both pain scores $(\mathrm{P}=0.05)$ and opioid consumption $(\mathrm{P}$ $=0.93)$. The incidence of postoperative paralytic ileus, antiemetic administration, and time to first rescue opioid administration did not differ significantly among the three study groups.

Another randomized study performed by Ganapathy et al. ${ }^{(14)}$, included fifty adult patients undergoing open abdominal surgery via laparotomy. They were allocated randomly to receive preoperative catheter-congruent TEA or ultrasound-guided continuous bilateral Lateral to medial (LM) TAP block for $72 \mathrm{~h}$ postoperatively and found no statistical difference in pain scores between TEA and LM-TAP at rest $(\mathrm{P}=0.829)$ or at dynamic pain scores $(\mathrm{P}=0.551)$. The variability in pain scores was lower in the LM-TAP group than in the TEA group in the first $24 \mathrm{~h}$ postoperatively. Also no statistical difference between them in Patient satisfaction $(\mathrm{p}=0.5)$ time to pass flatus $(\mathrm{p}=0.94)$ However, morphine consumption in $2 \mathrm{nd}$ day only was higher in LM-TAP group $(\mathrm{p}=0.018)$ and TEA group prone to have significant hypotension $(\mathrm{p}=0.02)$.

These results differ from those of Kadam and Moran ${ }^{(15)}$, who found in, their study which included 42 patients compared continuous transversus abdominis plane block with continuous epidural analgesia for major abdominal surgery. No differences were found in regards to NRS pain scores ( $p \geq 0.1)$, either immediately postoperatively or after $72 \mathrm{~h}$, total opioid requirement $(\mathrm{p}=0.99)$ and satisfaction scores $(p=0.47)$ were also similar in both groups.

These results also differ from those collected by Kadam and Moran ${ }^{(16)}$. Their study included 15 patients with the TAP and 15 with thoracic epidural procedures. And showed low pain scores in the postanesthesia care unit (PACU) in favor of the epidural, but no analgesic difference was found subsequently between the two techniques $(p=0.62)$. The fentanyl requirement is less in epidural patients compared with those undergoing TAP $(\mathrm{P}=0.03)$. In addition, no statistical difference between two groups in patient satisfaction.

Another contradictory results to our data have been reported by Niraj et al. ${ }^{(17)}$. In their prospective analysis, compared continuous thoracic epidural analgesia to bilateral intermittent-bolus subcostal TAP catheters in open hepatobiliary and 
renal surgery patients. The authors observed no significant difference in VAS score $(\mathrm{p}=0.46)$, nausea score $(\mathrm{p}=0.20)$ and patient satisfaction $(\mathrm{p}=0.74)$ from 8 hours to 72 hours after surgery. However, Tramadol consumption over $72 \mathrm{~h}$ was significantly higher in the TAP group compared to the epidural group $(\mathrm{p}=0.002)$.

Another contradictory results to our data have been reported by Niraj et al. ${ }^{(18)}$, which compared the efficacy of continuous transversus abdominis plane analgesia with epidural analgesia in 70 patients following laparoscopic colorectal surgery. They had found no significant difference in visual analogue scores at $24 \mathrm{~h}$ between the transversus group and the epidural group ( $\mathrm{p}=0.47)$. Also there was no significant differences between the groups for tramadol consumption over $48 \mathrm{~h}(\mathrm{p}=0.48)$, Nausea scores $(p=0.43)$, time of ambulation $(p=0.06)$ and time to pass flatus $(\mathrm{p}=0.14)$. In addition the TAP group had a higher level of satisfaction $(\mathrm{p}=0.03)$.

\section{CONCLUSION}

This study concluded that TAP block was effective in pain relief after Laparoscopic sleeve gastrectomy but Lumber Epidural was superior in pain relief, less narcotic consumption and overall more patient satisfaction.

\section{REFERENCES}

1- Carr DB, Jacox AK, Chapman CR et al. (2011): Acute pain management: operative or medical procedures and trauma: Clinical Practice Guideline. Available at: https:// books. google. com. eg/ books? $\mathrm{hl}=\quad \operatorname{ar} \& \quad \mathrm{l}=\& \quad \mathrm{id}=\mathrm{xrzWlu} \quad$ RnmJcC\&o $\mathrm{i}=$ fnd\&pg $=$ PA1\&dq $=1-\% 09$ Carr $+\quad \mathrm{DB},+\quad$ Jacox + $\mathrm{AK},+$ Chapman Z+ CR+ et+al.+ (2011):+ Acute+pain+ management:+ operative+ or+medical+ procedures+and+ trauma:+ Clinicalt Practice+ Guideline,+ 92:+ 0032.\&ots= LIwyg7SlOG\&sig =wSTjqVn7kaLUiZ4C6-Mga44reV4 \& redir_esc $=$ $\mathrm{y} \# \mathrm{v}=$ onepage \&q\&f$=$ false

2- De Oliveira GS, Fitzgerald $P$, Streicher LF, Marcus RJ, McCarthy RJ (2012): Systemic lidocaine to improve postoperative quality of recovery after ambulatory laparoscopic surgery. Anesth Analg., 115(2): 262-267.

3- Chin KJ, Perlas A, Chan VW, Brull R (2008): Needle visualization in ultrasound-guided regional anesthesia: challenges and solutions. Reg Anesth Pain Med., 33(6): 532-544.
4- Park WY, Thompson JS, Lee KK (2001): Effect of Epidural Anesthesia and Analgesia on Perioperative Outcome. Ann Surg., 234(4): 560-571.

5- McDonnell JG, O'Donnell B, Curley G, Heffernan A, Power C, Laffey JG (2007): The analgesic efficacy of transversus abdominis plane block after abdominal surgery: a prospective randomized controlled trial; Anesth Analg., 104(5): 1108.

6- Breivik $H$ and Stubhaug A. (2008): Management of acute postoperative pain: still a long way to go! Pain, 137(2): 233-234.

7- Hung WC, Chen WH, Shih YH, Email KC (2015): Epidural anesthesia for laparoscopic bariatric surgery: a case report, Springer Plus, 4(1):363.

8- Dolin SJ, Cashman JN, Bland JM (2002): Effectiveness of acute postoperative pain management Evidence from published data. British Journal of Anaesthesia, 89 (3): 409-423.

9- Milan Z, Tabor D, McConnell P, Pickering J, Kocarev M, du Feu F, Barton S (2011): Three different approaches to transversus abdominis plane block: a cadaveric study. Med Glas (Zenica), 8(2): 181-4.

10- Yiquan W, Fuli L, Hongli T, Quanguang W, Limei C, Hui W (2013): The Analgesic Efficacy of Subcostal Transversus Abdominis Plane Block Compared with Thoracic Epidural Analgesia and Intravenous Opioid Analgesia After Radical Gastrectomy. Anesth Analg., 117: 507-13.

11- Wahba SS and Kamal SM (2014): Analgesic efficacy and outcome of transversus-abdominis plane block versus low thoracic-epidural analgesia after laparotomy in ischemic heart disease patients. Journal of Anesthesia, 28: 4: 517-523.

12- Sherif AA, Hala MK, Samer MS (2013): Feasibility and perioperative pain-relieving efficacy of ultrasound guided transversus abdominis plane block in morbidly obese patients undergoing laparoscopic bariatric surgery. Research and Opinion in Anesthesia \& Intensive Care, 1(2):50-56.

13- Ayad S, Rovnat B, Hesham E, Vinayak N, Chetan L, Natalya M (2016): Comparison of Transversus Abdominis Plane Infiltration with Liposomal Bupivacaine versus Continuous Epidural Analgesia versus Intravenous Opioid Analgesia: PLoS ONE, 11(4): e0153675. 
14- Ganapathy S, Rakesh VS, Magdalena T, Jonathan B, Sanjib D (2015): Comparison of efficacy and safety of lateral-to-medial continuous transversus abdominis plane block with thoracic epidural analgesia in patients undergoing abdominal surgery; Eur $\mathrm{J}$ Anaesthesiol., 32:797-804.

15- Kadam VR, Moran JL, Van Wijk RM, Miller D (2013): Epidural versus continuous transversus abdominis plane catheter technique for postoperative analgesia after abdominal surgery: Anaesth Intensive Care, 41: 476-481.

16- Kadam VR and Moran JL (2011): Epidural infusions versus transversus abdominis plane (TAP) block infusions: retrospective study, Journal of Anesthesia, 25(5); 786-787.
17- Niraj G, Kelkar A, Jeyapalan I, Graff-Baker P, Williams O, Darbar A, (2011): Comparison of analgesic efficacy of subcostal tranversus abdominis plane blocks with epidural analgesia following upper abdominal surgery; Anaesthesia, 66:465-71.

18- Niraj G, Kelkar A, Hart E, Horst C, Malik D, Yeow C (2014): Comparison of analgesic efficacy of four-quadrant transversus abdominis plane (TAP) block and continuous posterior TAP analgesia with epidural analgesia in patients undergoing laparoscopic colorectal surgery, 69(4):348-55. 